\title{
Identification of Sources of Quantitative Resistance to Fusarium oxysporum f. sp. medicaginis in Medicago truncatula
}

\author{
N. Rispail and D. Rubiales, CSIC, Institute for Sustainable Agriculture, Alameda del Obispo s/n, Apdo. 4084, 14080 Córdoba, Spain
}

\begin{abstract}
Rispail, N., and Rubiales, D. 2014. Identification of sources of quantitative resistance to Fusarium oxysporum f. sp. medicaginis in Medicago truncatula. Plant Dis. 98:667-673.

The resistance of 267 Medicago truncatula accessions was determined against the soilborne pathogen Fusarium oxysporum, one of the major constraints of forage and grain legumes worldwide. The initial screening of the collection revealed a wide range of disease response from completely resistant to highly susceptible to one strain of $F$. oxysporum f. sp. medicaginis. As a result, 26 accessions were identified as resistant, 9 as susceptible, and all other accessions as partially resistant. The phenotype of 12 resistant accessions was confirmed in two independent experiments on a subset of 23 accessions. Quantification of $F$. oxysporum f. sp. medicaginis within plant tissue indicated that the

oxysporum f. sp. medicaginis within its shoot. Inoculation with a different $F$. oxysporum f. sp. medicaginis isolate indicated that the resistance phenotype was stable because accession response to both $F$. oxysporum f. sp. medicaginis strains followed similar trends. However, grouping accessions according to their geographic origin did not reveal foci of resistance, which supports the idea that resistance arose from independent events. The identification of 12 resistant accessions will be useful for further cellular and molecular studies to unravel the basis of resistance to $F$. oxysporum in this model species and to transfer resistance to legume crop.
\end{abstract} resistance level of the accessions is correlated with the amount of $F$.
Fusarium wilt, caused by the soilborne ascomycete fungus Fusarium oxysporum Schltdl., is one of the major constraints of forage and grain legumes worldwide $(16,20,26)$. Several races and pathotypes have been identified for most legume-infecting formae speciales based on their virulence on subsets of differential hosts and their molecular and genetic characterization (20). Thus, four races have been identified thus far for the pea (Pisum sativum L.) pathogen $F$. oxysporum f. sp. pisi $(20,25,26)$ and eight races and two pathotypes for the chickpea (Cicer arietinum L.) pathogen $F$. oxysporum f. sp. ciceris (23). By contrast, no physiological specialization has been described thus far for $F$. oxysporum $\mathrm{f}$. sp. lentis or F. oxysporum f. sp. medicaginis that infect lentil (Lens culinaris Med.) and alfalfa (Medicago sativa L.), respectively $(11,20)$. As for many soilborne pathogenic fungi, control of this disease is difficult and requires the integration of several disease management methods, among which utilizing host resistance is the most effective method (27). Fortunately, monogenic resistance to $F$. oxysporum has been described for most legume crops (20) and used to develop resistant cultivars to control the disease (20). However, this qualitative resistance can be rapidly overcome by the emergence of new pathogen variants such as in chickpea and pea $(3,37)$. Breeding programs that incorporate resistance sources with quantitative and polygenic mechanisms would improve the durability of resistance. However, this requires a better understanding of the molecular and cellular basis of the resistance in legumes to direct breeding strategies and contribute to a more efficient and durable breeding.

Barrel medic ( $M$. truncatula L.) is an important pasture legume (7) that has recently emerged as a model plant species for struc-

Corresponding author: N. Rispail, E-mail: nrispail@ias.csic.es

* The $e$-Xtra logo stands for "electronic extra" and indicates that a supplementary table is available online and that Figure 1 appears in color online.

Accepted for publication 21 November 2013.

http://dx.doi.org/10.1094/PDIS-03-13-0217-RE

(C) 2014 The American Phytopathological Society tural and functional genomics $(6,14)$. $M$. truncatula is closely related to cultivated alfalfa and to other legumes such as pea, chickpea, faba bean (Vicia faba L.), and lentils. This close phylogenic relationship increases the value of $M$. truncatula as a resource for understanding the important agronomic traits of grain and forage legumes, including their resistance to diseases (35). As such, this model legume has been already used to dissect the genetic, cellular, or molecular basis of resistance to six legume pathogens or pests (1,4,5,9,12,31-33,36,38-40). A recent study also used $M$. truncatula to provide valuable information on molecular and cellular aspects of the $M$. truncatula-F. oxysporum interaction in the context of susceptibility. However, this research did not identify resistant $M$. truncatula genotypes (34). To understand the molecular basis underlying resistance, it is important to identify and characterize resistant accessions. To this aim, we screened a wide collection of $M$. truncatula accessions of worldwide origin to identify resistance to $F$. oxysporum f. sp. medicaginis.

\section{Materials and Methods}

Fungal isolates and culture conditions. $F$. oxysporum f. sp. medicaginis isolates MIAE00930 (strain 605) and MIAE01129 (strain 179.29) were obtained from the Microorganismes d'Intérêt AgroEnvironnemental (MIAE) collection of UMR Agroecology, INRA Dijon, France. Strain 179.29 is a reference strain of $F$. oxysporum f. sp. medicaginis of unknown origin while strain 605 was originally collected in Greece. Both strains are equally pathogenic on $M$. truncatula (34). Thus, strain 605 was used in all experiments while strain 179.29 was used to test the stability of the resistance phenotype on a subset of $M$. truncatula accessions between $F$. oxysporum f. sp. medicaginis isolates. The fungal strains were routinely stored as microconidial suspensions at $-80^{\circ} \mathrm{C}$ with $30 \%$ glycerol. For microconidia production, cultures were grown in potato dextrose broth (Difco) at $28^{\circ} \mathrm{C}$ with shaking at $170 \mathrm{rpm}(8)$.

Plant material and growth conditions. A collection of 267 accessions of $M$. truncatula of worldwide distribution, kindly provided by the United States Department of Agriculture-Agricultural Research Service germplasm collection, was used in this study. The collection contained mainly wild accessions (78\%) originating from Mediterranean countries, although many cultivars and breeding materials developed in Australia and additional countries were also included. 
M. truncatula seed were wrapped in wet filter paper in a petri dish, stratified for 2 days at $4^{\circ} \mathrm{C}$ in the dark, and incubated at $20 \pm$ $2^{\circ} \mathrm{C}$ until germination. Once germinated, seedlings were transferred to pots $\left(36 \mathrm{~cm}^{2}\right.$ by $8 \mathrm{~cm}$ ) containing sterile vermiculite ( 1 to $3 \mathrm{~mm}$ diameter) and grown in a controlled environment chamber under a photoperiod of $16 \mathrm{~h}$ of light and $8 \mathrm{~h}$ of darkness. Temperatures were maintained at $25^{\circ} \mathrm{C}$ during the day and $22 \pm$ $2^{\circ} \mathrm{C}$ at night, with $200 \mu \mathrm{mol} \mathrm{m} \mathrm{m}^{-2} \mathrm{~s}^{-1}$ of illumination. Plants were watered every 3 days with tap water and weekly with Hoagland nutrient solution (19).

Inoculation and disease assessment. Twenty-day-old $M$. truncatula seedlings (two to three leaves) were inoculated following a modified version of the dip technique described by Haglund (17). For this, roots were removed from vermiculite, cleaned, and dipped for $30 \mathrm{~min}$ in a suspension containing microconidia at $5 \times 10^{6} / \mathrm{ml}$ of water. Control plants were immersed in sterile water. Seedlings were planted in individual 50-ml tubes containing autoclaved vermiculite and maintained in above mentioned growth chamber.

The screening of the entire collection was performed once on five seedlings per $M$. truncatula accession using the 605 isolate. The resistance reaction of 18 of the 26 highly resistant accessions of $M$. truncatula was validated and contrasted with the reaction of two representative partially resistant accessions and three susceptible accessions in two independent experiments (Table 1). For these validation experiments, inoculations were performed with the same F. oxysporum f. sp. medicaginis strain (strain 605) on five seedlings per accession and experiment. Preliminary statistical tests (oneway analysis of variance [ANOVA]) did not detect significant differences between these repetitions; thus, the results obtained were combined before further analysis.

To evaluate the stability of the resistance, a representative subset of the M. truncatula collection was challenged with strain 179.29 in two independent experiments, each using 10 seedlings per accession and experiment. This subset comprised $12 \mathrm{M}$. truncatula accessions: 4 resistant (W6 5976, PI 577616, PI 577618, and PI 577629), 5 partially resistant (PI 197358, PI 283662, PI 577619,
W6 5964, and W6 5978), and 3 susceptible (PI 239879, PI 516927, and PI 577607).

For all experiments, F. oxysporum f. sp. medicaginis symptoms were rated every 3 days from 8 to 35 days post inoculation (dpi) on a scale from 1 to 10 , corresponding to the following phenotypes: 1 = healthy plant (no symptoms), 2 = first leaf chlorosis, $3=<25 \%$ of the leaves showing symptoms (both leaf chlorosis and necrosis), $4=<50 \%$ of the leaves with symptoms, $5=<75 \%$ of the leaves showing symptoms, $6=$ between 75 and $100 \%$ of the leaves with symptoms, $7=100 \%$ of the leaves with symptoms, $8=100 \%$ of the leaves with necrosis, $9=$ initiation of stem and petiole drying and collapsing, $10=$ dead plants. These data were used to calculate the area under the disease progression curve (AUDPC) for each plant, as described previously (3).

Quantification of $\boldsymbol{F}$. oxysporum f. sp. medicaginis in planta. In planta quantification of $F$. oxysporum strain 605 was performed by real-time quantitative polymerase chain reaction (qPCR). For this, $12 \mathrm{M}$. truncatula seedlings were grown and inoculated with strain 605 as described above. After 8 days, the shoots of nine seedlings were harvested, weighed, and frozen under liquid nitrogen before storing at $-80^{\circ} \mathrm{C}$. DNA was extracted from frozen tissue according to the cetyltrimethylammonium bromide protocol (30) and quantified in triplicate with a Nanodrop-1000 spectrophotometer (Thermo Scientific). All DNA samples were then adjusted to a

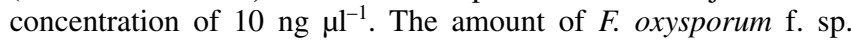
medicaginis DNA within each accession was then estimated by qPCR on a Step One Real-time PCR system (Applied Biosystems) following the method previously described (22) on three independent samples per accession, each sample consisting of the shoots of three plants pooled together. In parallel, the remaining three seedlings were maintained in the growth chamber and use to evaluate $F$. oxysporum f. sp. medicaginis disease development, as described above.

Statistical analysis. To analyze the significance of the differences in $F$. oxysporum f. sp. medicaginis disease rating and in the amount of $F$. oxysporum f. sp. medicaginis DNA between $M$. trun-

Table 1. Disease rating of a representative selection of Medicago truncatula accessions to Fusarium oxysporum f. sp. medicaginis isolate MIAE00930 (strain $605)^{\mathrm{x}}$

\begin{tabular}{|c|c|c|c|c|c|}
\hline \multirow[b]{2}{*}{ Accessions } & \multirow[b]{2}{*}{ Class $^{y}$} & \multicolumn{3}{|c|}{ Disease index } & \multirow[b]{2}{*}{$\mathbf{A U D P C}^{\mathbf{z}}$} \\
\hline & & 10 dpi & 20 dpi & 30 dpi & \\
\hline W6 5976 & $\mathrm{R}$ & $1.17 \pm 0.08 \mathrm{a}$ & $1.36 \pm 0.17 \mathrm{a}$ & $2.16 \pm 0.42 \mathrm{a}$ & $16.1 \pm 5.29 \mathrm{a}$ \\
\hline PI 577600 & $\mathrm{R}$ & $1.02 \pm 0.00 \mathrm{a}$ & $1.61 \pm 0.24 \mathrm{a}$ & $2.06 \pm 0.23 \mathrm{a}$ & $17.8 \pm 4.64 \mathrm{a}$ \\
\hline PI 577629 & $\mathrm{R}$ & $1.03 \pm 0.09 \mathrm{a}$ & $1.38 \pm 0.20 \mathrm{a}$ & $2.56 \pm 0.38 \mathrm{a}$ & $21.1 \pm 4.46 \mathrm{a}$ \\
\hline PI 577640 & $\mathrm{R}$ & $1.48 \pm 0.20 \mathrm{a}$ & $1.78 \pm 0.41 \mathrm{a}$ & $1.93 \pm 0.44 \mathrm{a}$ & $23.2 \pm 10.30 \mathrm{a}$ \\
\hline PI 577618 & $\mathrm{R}$ & $1.22 \pm 0.14 \mathrm{a}$ & $1.82 \pm 0.17 \mathrm{a}$ & $3.02 \pm 0.22 \mathrm{a}$ & $31.8 \pm 3.23 \mathrm{a}$ \\
\hline PI 577646 & $\mathrm{R}$ & $1.25 \pm 0.22 \mathrm{a}$ & $1.54 \pm 0.23 \mathrm{a}$ & $3.38 \pm 0.30$ & $34.5 \pm 5.30 \mathrm{a}$ \\
\hline PI 577616 & $\mathrm{R}$ & $1.31 \pm 0.19 \mathrm{a}$ & $2.31 \pm 0.30 \mathrm{a}$ & $3.23 \pm 0.20$ & $38.3 \pm 6.03 \mathrm{a}$ \\
\hline PI 577630 & $\mathrm{R}$ & $1.19 \pm 0.11 \mathrm{a}$ & $2.24 \pm 0.24 \mathrm{a}$ & $3.60 \pm 0.37$ & $41.9 \pm 5.77 \mathrm{a}$ \\
\hline PI 197358 & $\mathrm{R}$ & $1.34 \pm 0.16 \mathrm{a}$ & $2.80 \pm 0.36 \mathrm{a}$ & $3.51 \pm 0.40$ & $43.3 \pm 7.50 \mathrm{a}$ \\
\hline PI 535552 & $\mathrm{R}$ & $1.57 \pm 0.24 \mathrm{a}$ & $2.03 \pm 0.34 \mathrm{a}$ & $4.00 \pm 0.32$ & $46.9 \pm 7.51 \mathrm{a}$ \\
\hline PI 577645 & $\mathrm{R}$ & $1.94 \pm 0.30 \mathrm{a}$ & $2.22 \pm 0.32 \mathrm{a}$ & $3.58 \pm 0.33$ & $48.1 \pm 8.21 \mathrm{a}$ \\
\hline PI 197360 & $\mathrm{R}$ & $1.74 \pm 0.20 \mathrm{a}$ & $3.11 \pm 0.22$ & $3.43 \pm 0.22$ & $50.0 \pm 5.34$ \\
\hline PI 442892 & $\mathrm{R}$ & $2.35 \pm 0.31$ & $2.74 \pm 0.38 b$ & $3.54 \pm 0.37$ & $54.6 \pm 10.53$ \\
\hline PI 535554 & $\mathrm{R}$ & $2.43 \pm 0.47$ & $2.74 \pm 0.40 \mathrm{a}$ & $3.54 \pm 0.32$ & $56.5 \pm 10.26$ \\
\hline PI 577619 & $\mathrm{R}$ & $2.26 \pm 0.43$ & $2.61 \pm 0.43 \mathrm{a}$ & $3.88 \pm 0.31$ & $56.7 \pm 9.97$ \\
\hline PI 577641 & $\mathrm{R}$ & $2.34 \pm 0.28$ & $2.95 \pm 0.35$ & $3.83 \pm 0.24$ & $61.3 \pm 8.50$ \\
\hline PI 384636 & $\mathrm{R}$ & $2.36 \pm 0.33$ & $3.67 \pm 0.55$ & $3.95 \pm 0.55$ & $65.9 \pm 14.57$ \\
\hline PI 516923 & $\mathrm{R}$ & $2.88 \pm 0.46$ & $3.56 \pm 0.41$ & $4.46 \pm 0.23$ & $76.6 \pm 9.79$ \\
\hline PI 442895 & $\mathrm{P}$ & $2.75 \pm 0.43$ & $4.10 \pm 0.33$ & $4.24 \pm 0.28$ & $84.5 \pm 8.16$ \\
\hline PI 283661 & $\mathrm{P}$ & $3.40 \pm 0.35$ & $3.70 \pm 0.29$ & $4.74 \pm 0.40$ & $86.0 \pm 8.07$ \\
\hline PI 239878 & $\mathrm{~S}$ & $5.03 \pm 0.47 b$ & $7.62 \pm 0.46 b$ & $8.17 \pm 0.38 b$ & $181.3 \pm 13.27 b$ \\
\hline PI 577607 & $\mathrm{~S}$ & $6.37 \pm 0.29$ & $8.95 \pm 0.32$ & $9.49 \pm 0.24$ & $216.6 \pm 7.37$ \\
\hline PI 516927 & $\mathrm{~S}$ & $6.58 \pm 0.50$ & $8.46 \pm 0.37 b$ & $9.44 \pm 0.31$ & $221.0 \pm 11.99$ \\
\hline
\end{tabular}

${ }^{x}$ Accessions were chosen following the screening of the whole collection against this $F$. oxysporum f. sp. medicaginis isolate in order to validate the resistance phenotype of most of the resistant accessions originally detected (Supplementary Table S1). Data are means \pm standard error of 15 replicates; dpi = days post inoculation. Letter indicates that the accession is not significantly different from the (a) resistant PI 577600 or (b) susceptible PI 239878 reference accessions as determined by analysis of variance with contrast analysis at $P=0.05$.

${ }^{\mathrm{y}}$ Previous classification of accessions according to the result of the screening of the entire collection. $\mathrm{R}=$ resistant, $\mathrm{P}=$ partial resistance, and $\mathrm{S}=$ susceptible.

${ }^{\mathrm{z}}$ Area under the disease progression curve. 
catula accessions, all data were subjected to a one-way ANOVA. Whenever this test was statistically significant $(P \leq 0.05)$, contrast analysis (Scheffe) assessing the differences of the means between each accession with the resistant accession PI 577600 or the susceptible PI 239878 were performed to separate accessions according to their disease ratings. A Scheffe mean comparison test was also performed to separate accessions according to the amount of F. oxysporum f. sp. medicaginis DNA they contained.

\section{Results}

On highly susceptible accessions such as PI 239878 and PI 577607, initial symptoms appeared on the first leaf around 7 dpi and sequentially reached the later-formed leaves until the whole plant withered and died. This sequential appearance of disease symptoms allowed us to evaluate the plants according to the 1-to10 disease scale described above (Fig. 1A). Three types of disease progressions were observed (Fig 1B). Susceptible accessions, including PI 577607 and PI 239878, showed symptoms evolving rapidly, with disease ratings higher than 5 at 10 dpi and almost dead at 20 dpi (Fig. 1B). Resistant accessions such as PI 577600 and P I577618 showed almost no symptoms over the evaluation period, with disease ratings less than 4 at 30 dpi. Intermediate reactions, including the accessions W6 5978, W6 5964, and A17, showed intermediate symptom development, with disease ratings comprised between 4 and 8 at 30 dpi (Fig. 1B). Classification of accessions according to their AUDPC values showed a wide variety of responses from resistant to susceptible following a Gaussian distribution of the accessions indicative of the presence of quantita- tive mechanisms (Fig. 1C). Comparison of the AUDPC values obtained for each accession allowed us to separate three broad categories of disease responses and set the limits of these groups (Fig. 1C). Contrast analysis identified 26 accessions that were not significantly different from the resistant accession PI 577600 (Supplementary Table 1). Among them, eight accessions (3\%), including the resistant reference PI 577600, developed almost no symptoms and were characterized by AUDPC values lower than 25 and disease indexes $<1.3$ at $10 \mathrm{dpi},<2$ at $20 \mathrm{dpi}$, and $<3.5$ at $30 \mathrm{dpi}$. These accessions were considered to be highly resistant (Fig. 1C) while the other 18 accessions (6.7\%), showing AUDPC values between 25 and 50 and disease indexes $<2$ at $10 \mathrm{dpi},<4$ at $20 \mathrm{dpi}$, and $<6$ at 30 dpi were considered to be resistant. The contrast analysis also identified nine accessions (3.4\%) that were not significantly different from the susceptible accession PI 239878. These accessions were characterized by AUDPC values higher than 175 and disease indexes $>4$ at $10 \mathrm{dpi},>7$ at $20 \mathrm{dpi}$, and $>7.9$ at 30 dpi and were considered to be susceptible. Finally, 232 accessions (86.9\%) showed AUDPC values between 50 and 150 and were considered to be partially resistant/susceptible (Fig. 1C).

Grouping of M. truncatula accessions as wild or breeding material showed moderate levels of resistance within both categories. Wild accessions were slightly more susceptible, with higher mean AUDPC values (AUDPC $=104.5$ ) than cultivated or breeding accessions $($ AUDPC $=92.7$ ) (Fig. 2A). Because the collection contains accessions of $M$. truncatula from many different countries, wild accessions were classified according to their geographic origins to test whether resistance was focused on a specific geo-

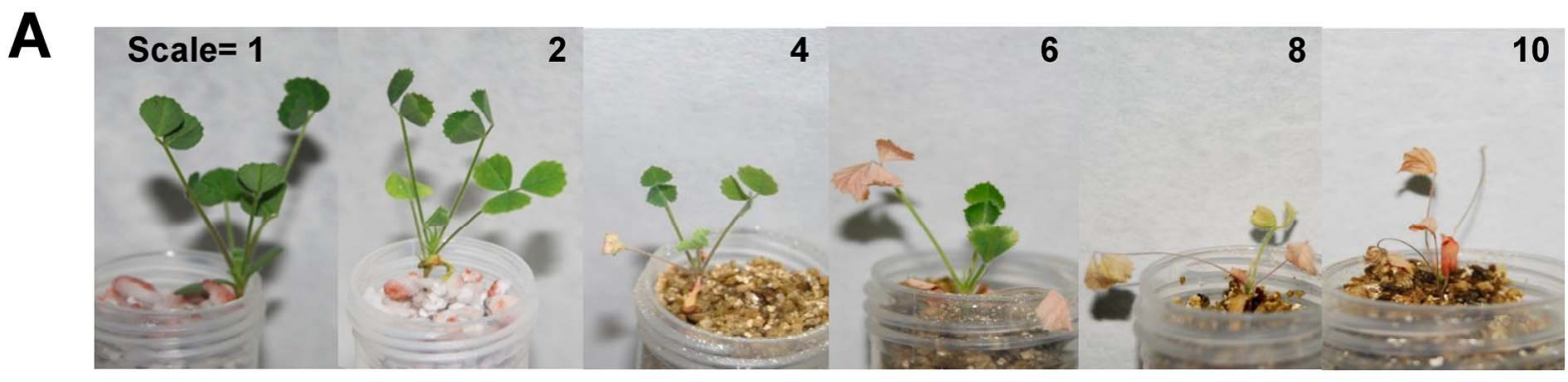

B

C
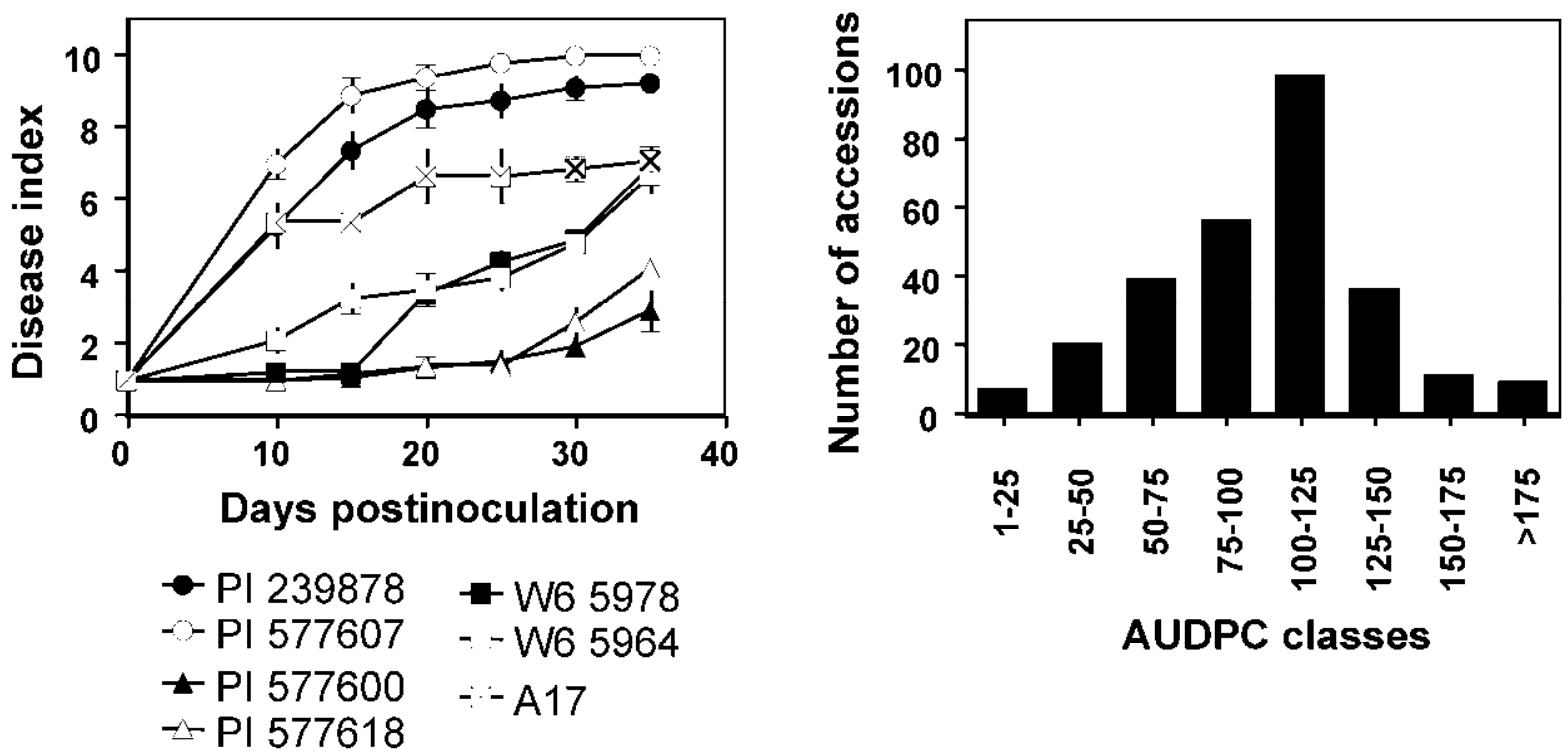

AUDPC classes

Fig. 1. Assessment of Fusarium oxysporum f. sp. medicaginis disease symptoms in the Medicago truncatula collection. A, Photographs represent the evolution of disease symptoms induced by F. oxysporum f. sp. medicaginis isolate MIAE00930 (strain 605) on susceptible M. truncatula accessions. Numbers within each photograph indicate its respective disease rating value based on a disease index scale ranging from 1 (healthy plant) to 10 (dead plant). B, Evolution of disease symptoms of different $M$. truncatula accessions differing in their susceptibility to strain 605. C, Distribution of $M$. truncatula accessions upon inoculation with strain 605 according to area under the disease progression curve (AUDPC) values calculated from the evaluation of disease ratings. 
graphic location or whether it occurred independently worldwide. With the exception of accessions from the Middle East (Turkey and Lebanon) that tended to be more susceptible to strain 605, with mean AUDPC values of 146.5 and 235, respectively, accessions from all other countries presented moderate levels of resistance, with mean AUDPC values ranging from 88 for Tunisia to 118.6 for Morocco (Fig. 2B).

The resistant phenotype of 18 accessions was contrasted with the phenotype of two partially resistant and three susceptible accessions in two independent evaluations of their disease response to strain 605 (Table 1). This assessment confirmed the highly resistant phenotype to this strain of $F$. oxysporum $\mathrm{f}$. sp. medicaginis for 12 of the 18 resistant accessions. These 12 accessions had AUDPC values lower than 50, and disease ratings were not statistically different from disease ratings on PI 577600, the resistant reference $(P \leq 0.05$; Table 1$)$. The other seven accessions showed varying level of partial resistance, with a disease index $<4$ at $20 \mathrm{dpi}$ and $<5.5$ at 30 dpi and an AUDPC values higher than 50, which was not significantly distinct from the AUDPC values observed for the partial resistant accessions PI 442895 and PI $283661(P>$ $0.05)$. In turn, the AUDPC values of these partially resistant accessions were largely and significantly lower than the 181.31 AUDPC value of the susceptible reference PI $239878(P<0.05$; Table 1$)$.

To determine whether observed resistance was due to resistance mechanisms per se or to tolerance mechanisms, the amount of

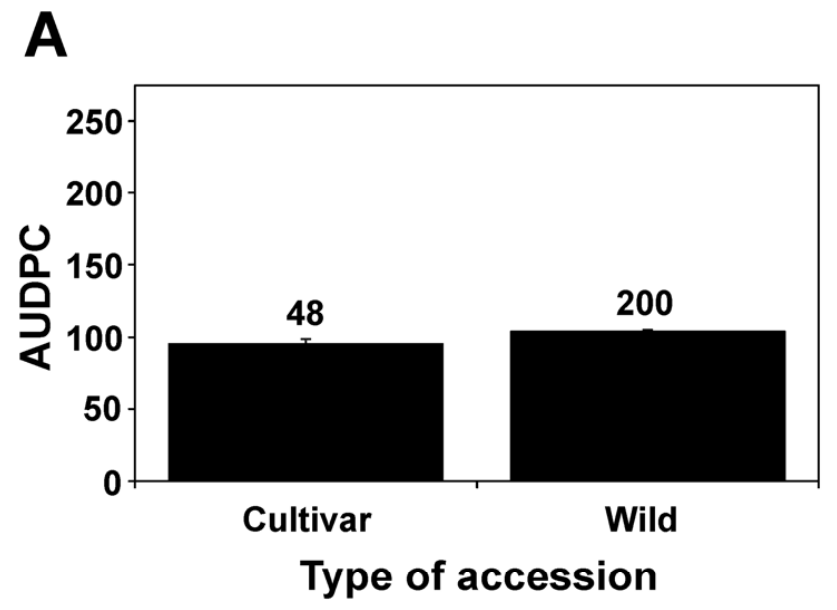

B

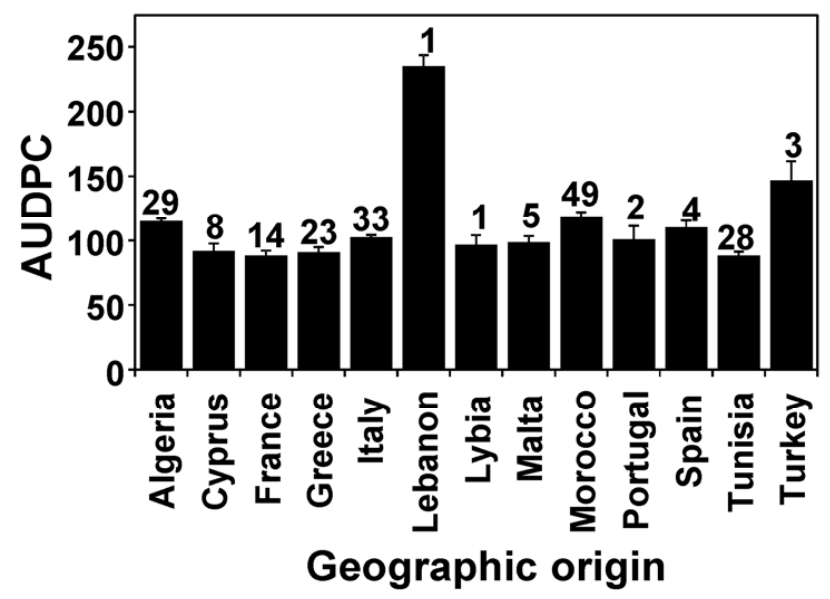

Fig. 2. Assessment of disease response to Fusarium oxysporum f. sp. medicaginis of the Medicago truncatula collection after classification of accessions according to A, type of material and B, geographical origin. Histograms represent the mean area under the disease progression curve (AUDPC) value for each group calculated from the evaluation of disease ratings. Vertical bars are standard errors. Numbers indicate the number of $M$. truncatula accessions. strain 605 was quantified at 8 dpi within shoots of seven $M$. truncatula accessions, including two resistant (PI 577618 and W6 5976), two partially resistant (PI 283661 and A17), and three susceptible (PI 239878, PI 516927, and PI 577607). At this early stage, we could detect low amounts of $F$. oxysporum f. sp. medicaginis DNA in all samples. The comparison of the amount of strain 605 in these accessions indicated that susceptible accessions accumulated more $F$. oxysporum than the resistant ones (Fig. 3A). The relative amount of $F$. oxysporum DNA in the DNA samples of the susceptible accessions ranged from $0.32 \%$ in PI 516927 to $0.41 \%$ in PI 239878. In contrast, the relative amount of $F$. oxysporum DNA was 0.04 and $0.1 \%$ in the resistant accessions W6 5976 and PI 577618, respectively. Partially resistant accessions accumulated an intermediate quantity of $F$. oxysporum DNA of 0.14 to $0.18 \%$ (Fig. 3A). Significant differences were observed between each group by one-way ANOVA $(P<0.001)$. Interestingly, a positive correlation was found when plotting the relative amount of strain 605 DNA per sample DNA according to AUDPC value of each accession, as estimated by the linear regression curve $\left(r^{2}=0.77\right.$; Fig. 3B).

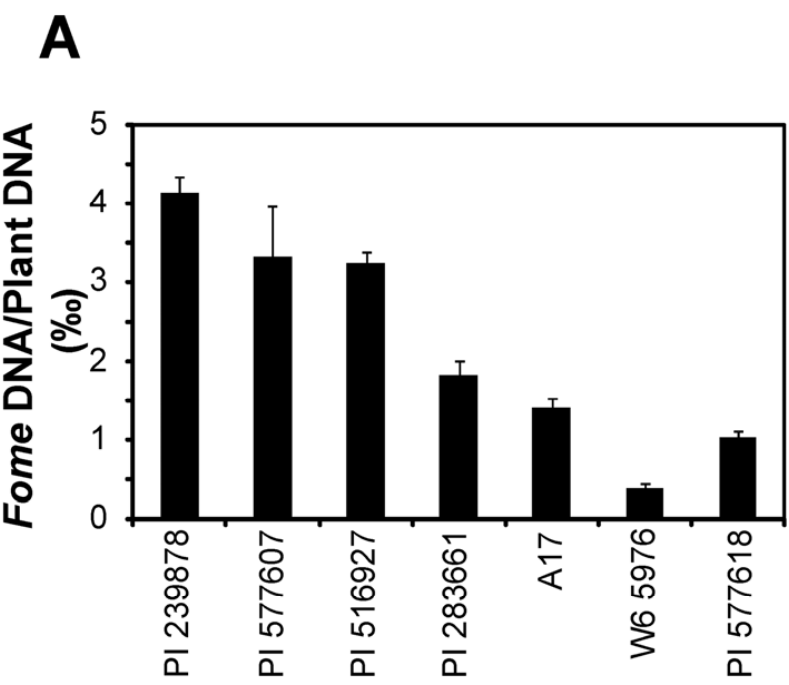

M. truncatula accessions

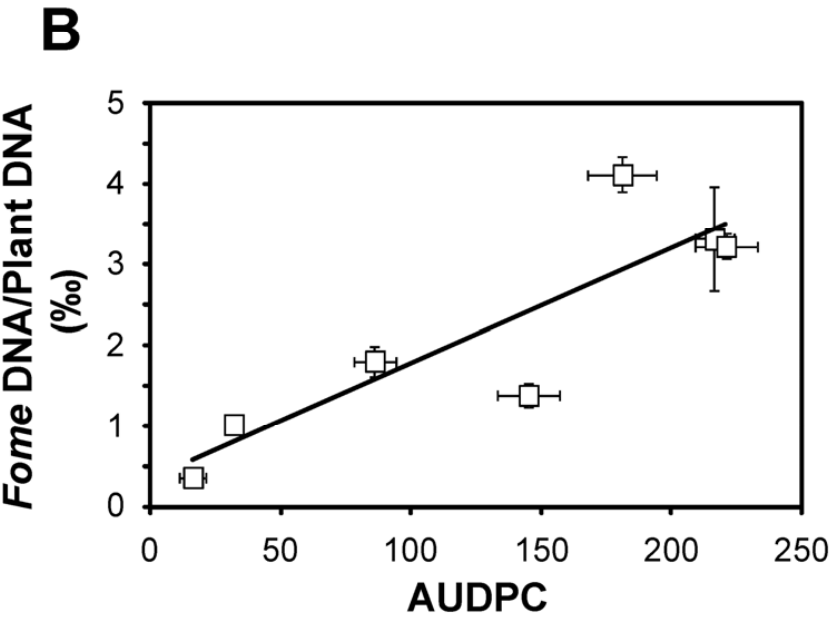

Fig. 3. In planta quantification of Fusarium oxysporum f. sp. medicaginis within plant tissue. A, The histogram represents the proportion of $F$. oxysporum f. sp. medicaginis DNA within plant DNA sample extracted from the shoot of different Medicago truncatula accessions 8 days after inoculation with strain 605 quantified by quantitative polymerase chain reaction assay (26). B, The graph represents the distribution of the amount of $F$. oxysporum $\mathrm{f}$. sp. medicaginis DNA within plant DNA sample according to the area under the disease progression curve (AUDPC) value of the sample. Positive correlation between both parameters was detected by drawing a linear regression curve $\left(r^{2}=0.77\right)$. Horizontal and vertical lines are the standard errors. 
To test whether the resistance response was maintained against other $F$. oxysporum f. sp. medicaginis isolates, we assessed disease development on a subset of 12 selected accessions following inoculation by isolates 605 and 179.29 (Fig. 4). Strain 179.29 was less aggressive than strain 605 . Thus, disease severity, estimated by the AUDPC values, only reached 64.2 for the most susceptible accession, PI 577607, with strain 179.29 , which was much lower than the AUDPC of 216.6 obtained for this accession when inoculated with strain 605 (Fig. 4). Nevertheless, plant response to both isolates followed a similar trend; the most resistant accessions to strain 605 were also the most resistant to strain 179.29, and the most susceptible accessions to strain 605 were most susceptible to strain 179.29. Only one accession, W6 5964, had a differential response between isolates showing partial resistance to strain 605 but a high resistance response to strain 179.29.

\section{Discussion}

Resistance against $F$. oxysporum $\mathrm{f}$. sp. medicaginis was assessed in a large $M$. truncatula collection and revealed a wide range of disease responses from completely resistant to highly susceptible, with most $M$. truncatula accessions showing a moderate to low level of resistance to the pathogen. In addition, we identified 12 completely resistant accessions that may be highly valuable for breeding programs and useful in improving our understanding of the resistance mechanisms leading to $F$. oxysporum resistance in legumes.

F. oxysporum f. sp. medicaginis have been described to be the causal agent of both vascular wilt and root and crown rot in alfalfa $(11,24)$. Fusarium wilt disease causes a series of external symptoms, including vein clearing, leaf epinasty, wilting, chlorosis, necrosis, and abscission leading to the complete plant wilting and death (28). By contrast, root and crown rot is characterized by cortical necrosis, stellar necrosis, and vascular browning of the root (10). As expected from previous studies $(2,34)$, inoculation with two $F$. oxysporum f. sp. medicaginis isolates induced a combination of the typical Fusarium wilt symptoms in the susceptible and partially resistant accessions of $M$. truncatula, which indicates that the $F$. oxysporum f. sp. medicaginis isolates used here cause Fusarium wilt and not root rot (Fig. 1A).

The detection of clear Fusarium wilt symptoms allowed the development of our methodology based on plant symptoms to evaluate the M. truncatula collection. Most previous studies on virulence of $F$. oxysporum f. sp. medicaginis were performed on alfalfa $(2,11,13)$. In these studies, disease rating was performed on adult plants according to the degree of tap root internal discoloration (11). This method requires the transversal section of the tap root, which is very difficult to perform on plants with thin root systems such as $M$. truncatula seedlings. Thus, evaluation of the leaf symptoms are preferred (34). In a previous study, Ramirez-Suero et al. (34) monitored the susceptibility to $F$. oxysporum f. sp. medicaginis of eight lines of $M$. truncatula in a miniature hydroponic culture system. The disease symptoms of inoculated $M$. truncatula plants were scored using a visual scale of 0 to 5 according to appearance of chlorosis and necrosis on cotyledons and first leaves, which allowed identification of one line (F83005.5) with moderate resistance to $F$. oxysporum f. sp. medicaginis (34). Although this method was successful in establishing susceptibility on very young plantlets, it was very difficult to apply to older seedlings. Indeed, past the seedling establishment period, $M$. truncatula showed very profuse growth, whereas Fusarium wilt symptoms are a more progressive event. Thus, a single inoculated plant often shows a mixture of phenotypes, including healthy, yellowing, chlorotic, necrotic, and dead leaves. In addition, cotyledon necrosis is often observed on older healthy plants, which impedes the use of this scale on older plants (data not shown). We adapted a new scale with a higher number of categories (from 1 to 10) to account for the presence of symptoms and the extent of diseased leaves, and also the later stages of disease progression, including the stem external discoloration and withering that precede plant death (Fig. 1A).
The screening for $F$. oxysporum $\mathrm{f}$. sp. medicaginis resistance of the $M$. truncatula collection with this modified scale revealed that it contained sufficient genetic variation to detect a wide range of responses to F. oxysporum f. sp. medicaginis, from complete resistance to high susceptibility (Table 1). Interestingly, we established a correlation between the amount of $F$. oxysporum $\mathrm{f}$. sp. medicaginis within plant tissue and the overall level of resistance or susceptibility of the accession (Fig. 3). Similar correlations between the extent of colonization and resistance level have been previously described in several species, including tomato, watermelon, and chickpea $(15,21,41)$. This suggests that resistance phenotypes for $F$. oxysporum are generally due to the presence of mechanisms that reduce or limit colonization of the pathogen (41). Results presented here on M. truncatula support this hypothesis.

On the other hand, the M. truncatula collection is composed of wild and cultivated M. truncatula accessions collected throughout the world, although most wild accessions came from countries of the Mediterranean area, including Algeria, Morocco, and Tunisia. Resistance in wild accessions has been found from most locations, including Morocco, Tunisia, Greece, and Italy (Fig. 2B). Resistant and susceptible accessions were often found in nearby areas. This would indicate that resistance to $F$. oxysporum $\mathrm{f}$. sp. medicaginis did not originate from a precise world region, which is confirmed by the analysis of accessions' responses to $F$. oxysporum $\mathrm{f}$. sp. medicaginis according to their geographic origin (Fig. 2B). This was similar to the situation found by McPhee et al. (29) in pea against two different races of $F$. oxysporum f. sp. pisi.

Resistance to legume-infecting $F$. oxysporum has been considered qualitative, with either a monogenic inheritance, including resistance to races 1,5 , and 6 of $F$. oxysporum f. sp. pisi and races 3 and 5 of $F$. oxysporum f. sp. ciceri; or oligogenic, including resistance to races $1 \mathrm{~A}, 2$, and 4 of $F$. oxysporum f. sp. ciceri conferred by two to three genes (20). Previous studies on the tetraploid alfalfa indicated that resistance to $F$. oxysporum $\mathrm{f}$. sp. medicaginis in this plant species is also qualitative and controlled by at least two genes, one completely dominant $\left(\mathrm{FW}_{1}\right)$ and one with an additive effect $\left(\mathrm{FW}_{2}\right)(18)$. In the present study, we detected a continuity of responses from highly resistant to highly susceptible, with most accessions presenting moderate to low levels of resistance to F. oxysporum f. sp. medicaginis. Such continuity would support the existence of quantitative resistance mechanisms in the M. truncatula collection. This is similar to recent observations in a pea collection in response to one isolate of F. oxysporum $\mathrm{f}$. sp. pisi race

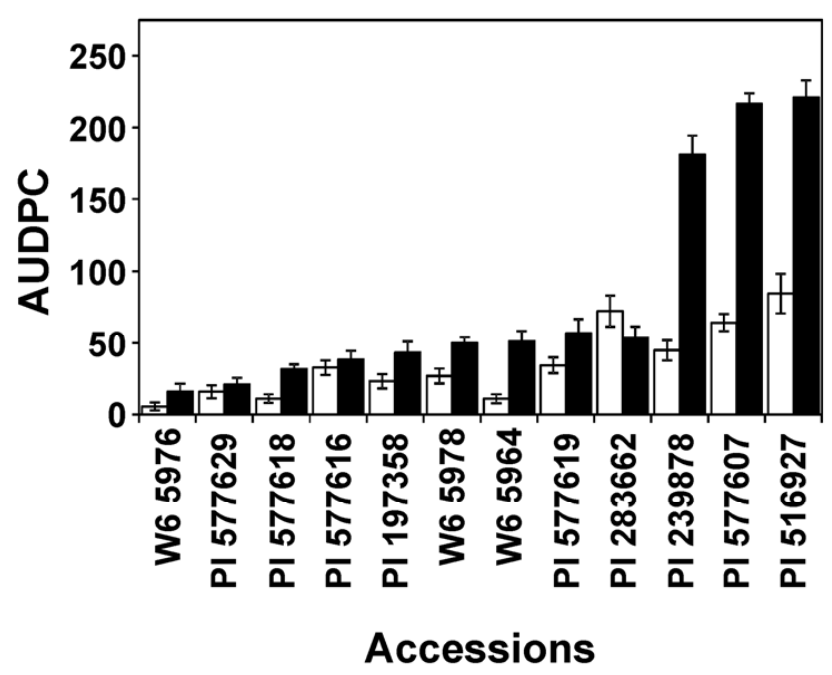

Fig. 4. Comparison of the response of 12 selected accessions to two isolates of Fusarium oxysporum f. sp. medicaginis. Solid and open bars indicate plants inoculated with strains 605 and 179.29, respectively. Data are means area under the disease progression curve (AUDPC) values calculated from the evaluation of disease ratings of 10 replications. Vertical lines are the standard errors. 
2 (3). However, genetic analysis of the M. truncatula accessions would be needed to confirm this hypothesis.

In the present study, two different isolates of $F$. oxysporum $\mathrm{f}$. sp. medicaginis were used to confirm the resistance phenotypes of selected accessions. Both isolates were pathogenic on susceptible accessions such as PI 577607 and PI 516927, although the second isolate (strain 179.29) was less aggressive than strain 605 (Fig. 4). Variation in aggressiveness between $F$. oxysporum f. sp. medicaginis isolates was observed when comparing isolates of different geographic origin $(11,24)$. Despite the aggressiveness difference of these strains, they induced a similar pattern of infection when inoculating the same accessions (13,24,34; Fig. 4). The similar plant responses to different $F$. oxysporum f. sp. medicaginis isolates could indicate a lack of physiological specialization of $F$. oxysporum f. sp. medicaginis, although molecular characterization of these isolates and additional testing of $F$. oxysporum f. sp. medicaginis isolates would be needed to ascertain this hypothesis.

This screening of a large collection of $M$. truncatula for resistance to $F$. oxysporum f. sp. medicaginis identified a variety of responses that will be aid in characterizing defense mechanisms that participate in $F$. oxysporum resistance at the cellular and molecular level. In particular, the identification of 12 resistant accessions will be a valuable tool to confer resistance to $F$. oxysporum in legume crops.

\section{Acknowledgments}

This work was supported by project AGL2011-22524 of the Spanish Ministry of Science and Innovation and co-financed by the European fund for regional development (FEDER). N. Rispail was holder of a "Juntas para la ampliación de estudios" postdoctorate (JAE-Doc) grant from the Consejo Superior de Investigaciones Científicas (CSIC). We thank C. Heraud for providing the fungal isolates and the United States Department of Agriculture-Agricultural Research Service for providing the $M$. truncatula accessions used in this study.

\section{Literature Cited}

1. Ameline-Torregrosa, C., Cazaux, M., Danesh, D., Chardon, F., Cannon, S. B., Esquerré-Tugayé, M. T., Dumas, B., Young, N. D., Samac, D. A., Huguet, T., and Jacquet, C. 2008. Genetic dissection of resistance to anthracnose and powdery mildew in Medicago truncatula. Mol. Plant-Microbe Interact. 21:61-69.

2. Antonopoulos, D. F., and Elena, K. 2008. Susceptibility of Greek alfalfa and clover cultivars to Fusarium oxysporum f. sp. medicaginis and potential methods of disease control. J. Plant Dis. Prot. 115:162-166.

3. Bani, M., Rubiales, D., and Rispail, N. 2012. A detailed evaluation method to identify sources of quantitative resistance to Fusarium oxysporum f. sp. pisi race 2 within a Pisum spp. germplasm collection. Plant Pathol. 61:532542.

4. Castillejo, M. A., Susin, R., Madrid, E., Fernandez-Aparicio, M., Jorrin, J. V., and Rubiales, D. 2010. Two-dimensional gel electrophoresis-based proteomic analysis of the Medicago truncatula-rust (Uromyces striatus) interaction. Ann. Appl. Biol. 157:243-257.

5. Colditz, F., Braun, H. P., Jacquet, C., Niehaus, K., and Krajinski, F. 2005. Proteomic profiling unravels insights into the molecular background underlying increased Aphanomyces euteiches-tolerance of Medicago truncatula. Plant Mol. Biol. 59:387-406.

6. Cook, D. R. 1999. Medicago truncatula-a model in the making! Curr. Opin. Plant Biol. 2:301-304.

7. Crawford, E. J., Lake, A. W. H., and Boyce, K. G. 1989. Breeding annual Medicago species for semiarid conditions in southern Australia. Adv. Agron. 42:399-437.

8. Di Pietro, A., and Roncero, M. I. G. 1998. Cloning, expression, and role in pathogenicity of $p g 1$ encoding the major extracellular endopolygalacturonase of the vascular wilt pathogen Fusarium oxysporum. Mol. PlantMicrobe Interact. 11:91-98.

9. Dita, M. A., Die, J. V., Roman, B., Krajinski, F., Kuester, H., Moreno, M. T., Cubero, J. I., and Rubiales, D. 2009. Gene expression profiling of Medicago truncatula roots in response to the parasitic plant Orobanche crenata. Weed Res. 49:66-80.

10. El Nasr, H. I. S., and Leath, K. T. 1983. Crown and root fungal diseases of alfalfa in Egypt. Plant Dis. 67:509-511.

11. Emberger, G., and Welty, R. E. 1983. Evaluation of virulence of Fusarium oxysporum f. sp. medicaginis and Fusarium wilt resistance in alfalfa. Plant Dis. 67:94-98.

12. Fernandez-Aparicio, M., Perez-de-Luque, A., Prats, E., and Rubiales, D. 2008. Variability of interactions between barrel medic (Medicago truncatula) genotypes and Orobanche species. Ann. Appl. Biol. 153:117-126.

13. Frosheiser, F. I., and Barnes, D. K. 1978. Field reaction of artificially inoculated alfalfa populations to the Fusarium and bacterial wilt pathogens alone and in combination. Phytopathology 68:943-946.

14. Frugoli, J., and Harris, J. 2001. Medicago truncatula on the move! Plant Cell 13:458-463.

15. Gao, H., Beckman, C. H., and Mueller, W. C. 1995. The rate of vascular colonization as a measure of the genotypic interaction between various cultivars of tomato and various formae or races of Fusarium oxysporum. Physiol. Mol. Plant Pathol. 46:29-43.

16. Gordon, T. R., and Martyn, R. D. 1997. The evolutionary biology of Fusarium oxysporum. Annu. Rev. Phytopathol. 35:111-128.

17. Haglund, W. A. 1989. A rapid method for inoculating pea seedlings with Fusarium oxysporum f. sp. pisi. Plant Dis. 73:457-458.

18. Hijano, E. H., Barnes, D. K., and Frosheiser, F. I. 1983. Inheritance of resistance to Fusarium wilt in alfalfa. Crop Sci. 23:31-34.

19. Hoagland, D. R., and Arnon, D. I. 1950. The water-culture method for growing plants without soil. Calif. Agric. Exp. Stn. Circ. 347:1-32.

20. Infantino, A., Kharrat, M., Riccioni, L., Coyne, C. J., McPhee, K. E., and Grunwald, N. J. 2006. Screening techniques and sources of resistance to root diseases in cool season food legumes. Euphytica 147:201-221.

21. Jimenez-Fernandez, D., Montes-Borrego, M., Jimenez-Diaz, R. M., NavasCortes, J. A., and Landa, B. B. 2011. In planta and soil quantification of Fusarium oxysporum f. sp. ciceris and evaluation of Fusarium wilt resistance in chickpea with a newly developed quantitative polymerase chain reaction assay. Phytopathology 101:250-262.

22. Jimenez-Fernandez, D., Montes-Borrego, M., Navas-Cortes, J. A., JimenezDiaz, R. M., and Landa, B. B. 2010. Identification and quantification of Fusarium oxysporum in planta and soil by means of an improved specific and quantitative PCR assay. Appl. Soil Ecol. 46:372-382.

23. Jimenez-Gasco, M. M., Navas-Cortes, J. A., and Jimenez-Diaz, R. M. 2004 The Fusarium oxysporum f. sp. ciceris/Cicer arietinum pathosystem: a case study of the evolution of plant-pathogenic fungi into races and pathotypes. Int. Microbiol. 7:95-104.

24. Kalb, D. W., Bergstrom, G. C., and Shields, E. J. 1994. Prevalence, severity and association of fungal crown and root rots with injury by the clover root Curculio in New-York alfalfa. Plant Dis. 78:491-495.

25. Kraft, J. M. 1994. Fusarium wilt of peas (a review). Agronomie 14:561-567.

26. Kraft, J. M., Larsen, R. C., and Inglis, D. A. 1998. Diseases of pea. In: The Pathology of Food and Pasture Legumes. D. J. Allen and J. M. Lenné, eds. CAB International, Wallingford, UK.

27. Landa, B. B., Navas-Cortes, J. A., and Jimenez-Diaz, R. M. 2004. Integrated management of Fusarium wilt of chickpea with sowing date, host resistance, and biological control. Phytopathology 94:946-960.

28. MacHardy, W. E., and Beckman, C. H. 1983. Vascular wilt fusaria: infection and pathogenesis. In: Fusarium: Diseases, Biology and Taxonomy. P. E. Nelson, T. A. Tousson, and R. J. Cook, eds. The Pennsylvania State University Press.

29. McPhee, K. E., Tullu, A., Kraft, J. M., and Muehlbauer, F. J. 1999. Resistance to Fusarium wilt race 2 in the Pisum core collection. J. Am. Soc. Hortic. Sci. 124:28-31.

30. Murray, M. G., and Thompson, W. F. 1980. Rapid isolation of high molecular weight plant DNA. Nucleic Acids Res. 8:4321-4325.

31. Nyamsuren, O., Colditz, F., Rosendahl, S., Tamasloukht, M., Bekel, T., Meyer, F., Küster, H., Franken, P., and Krajinski, F. 2003. Transcriptional profiling of Medicago truncatula roots after infection with Aphanomyces euteiches (oomycota) identifies novel genes upregulated during this pathogenic interaction. Physiol. Mol. Plant Pathol. 63:17-26.

32. Pilet-Nayel, M. L., Muehlbauer, F. J., McGee, R. J., Kraft, J. M., Baranger, A., and Coyne, C. J. 2005. Consistent quantitative trait loci in pea for partial resistance to Aphanomyces euteiches isolates from the United States and France. Phytopathology 95:1287-1293.

33. Prats, E., Llamas, M. J., and Rubiales, D. 2007. Characterization of resistance mechanisms to Erysiphe pisi in Medicago truncatula. Phytopathology 97:1049-1053.

34. Ramirez-Suero, M., Khanshour, A., Martinez, Y., and Rickauer, M. 2011. A study on the susceptibility of the model legume plant Medicago truncatula to the soil-borne pathogen Fusarium oxysporum. Eur. J. Plant Pathol. 126:517-530.

35. Rispail, N., Kalo, P., Kiss, G. B., Ellis, T. H. N., Gallardo, K., Thompson, R. D., Prats, E., Larrainzar, E., Ladrera, R., Gonzalez, E. M., Arrese-Igor, C., Ferguson, B. J., Gresshoff, P. M., and Rubiales, D. 2010. Model legumes contribute to faba bean breeding. Field Crops Res. 115:253-269.

36. Rubiales, D., and Moral, A. 2004. Prehaustorial resistance against alfalfa rust (Uromyces striatus) in Medicago truncatula. Eur. J. Plant Pathol. 110:239-243.

37. Sharma, A., Rathour, R., Plaha, P., Katoch, V., Khalsa, G. S., Patial, V., Singh, Y., and Pathania, N. K. 2010. Induction of Fusarium wilt (Fusarium oxysporum f. sp. pisi) resistance in garden pea using induced mutagenesis and in vitro selection techniques. Euphytica 173:345-356.

38. Torregrosa, C., Cluzet, S., Fournier, J., Huguet, T., Gamas, P., Prosperi, J. M., Esquerre-Tugaye, M. T., Dumas, B., and Jacquet, C. 2004. Cytological, genetic, and molecular analysis to characterize compatible and incompatible interactions between Medicago truncatula and Colletotrichum trifolii. Mol. Plant-Microbe Interact. 17:909-920.

39. Vailleau, F., Sartorel, E., Jardinaud, M. F., Chardon, F., Genin, S., Huguet, T., Gentzbittel, L., and Petitprez, M. 2007. Characterization of the interac- 
tion between the bacterial wilt pathogen Ralstonia solanacearum and the model legume plant Medicago truncatula. Mol. Plant-Microbe Interact. 20:159-167.

40. Yang, S., Gao, M., Xu, C., Gao, J., Deshpande, S., Lin, S., Roe, B. A., and Zhu, H. 2008. Alfalfa benefits from Medicago truncatula: the RCT1 gene from $M$. truncatula confers broad-spectrum resistance to anthracnose in alfalfa. Proc. Natl. Acad. Sci. USA 105:12164-12169.
41. Zhou, X. G., and Everts, K. L. 2004. Quantification of root and stem colonization of watermelon by Fusarium oxysporum $\mathrm{f}$. sp. niveum and its use in evaluating resistance. Phytopathology 94:832-841.

42. Zvirin, T., Herman, R., Brotman, Y., Denisov, Y., Belausov, E., Freeman, S., and Perl-Treves, R. 2010. Differential colonization and defence responses of resistant and susceptible melon lines infected by Fusarium oxysporum race 1.2. Plant Pathol. 59:576-585. 